\title{
LITERATURA E PRÁTICA TRANSLÍNGUE: REFLEXÕES SOBRE PORTUNHOL E POESIA
}

\author{
Literature and translanguaging: reflections on portunhol and poetry \\ Michele Cristina Ramos Gomes ${ }^{1}$ \\ Universidade Federal de Juiz de Fora \\ Ana Cláudia Peters Salgado ${ }^{2}$ \\ Universidade Federal de Juiz de Fora
}

Falar portunhol é tão natural quanto respirar

Fabián Severo

\begin{abstract}
RESUMO
O objetivo deste trabalho é refletir sobre o repertório linguístico (RYMES, 2014) presente na literatura escrita em portunhol e ponderar sobre a prática translíngue (CANAGARAJAH, 2013) que a perpassa. Além disso, esta pesquisa busca refletir sobre questões de identidade (SILVA, 2014) no que se relacionam às performances identitárias locais (MOITA LOPES, 2013) presentes nessa literatura. Para isso, selecionamos como objeto de estudo o poema "Trinticuatro", que faz parte do livro "Noite nu Norte” (2011), do escritor uruguaio nascido em Artigas, Fabián Severo. As reflexões qualitativas realizadas sobre o poema demonstraram a relevância do reconhecimento do portunhol enquanto língua, de importância identitária e artística. Além disso, corroboraram com a necessidade de pensar as línguas não mais a partir de uma perspectiva monolíngue, mas enquanto práticas locais por meio das quais os sujeitos agem no mundo de forma criativa segundo seus propósitos.
\end{abstract}

Palavras-chave: Prática translíngue. Repertório linguístico. Portunhol. Literatura

\begin{abstract}
This work aims to reflect on the linguistic repertoire (RYMES, 2014) present in the literature written in portunhol and to think about the translanguaging practice (CANAGARAJAH, 2013) that permeates $i t$. In addition, this research seeks to reflect on issues of identity (SILVA, 2014) as they relate to the local identity performances (MOITA LOPES, 2013) present in this literature. For that, we selected as an object of study the poem "Trinticuatro", which is part of the book "Noite nu Norte" (2011), by the Uruguayan writer born in Artigas, Fabian Severo. The reflections on the poem demonstrated the relevance of the recognition of the portunhol as a legitimate practice, of identity and artistic importance. Furthermore, they corroborated the need to think of languages no longer from a monolingual perspective, but as local practices through which subjects act creatively in the world according to their purposes.
\end{abstract}

Keywords: Translanguaging. Linguistic repertoire. Portunhol. Literature.

Recebido em: setembro 2018

Aceito em: abril 2019

DOI: $\underline{10.26512 / l e s . v 20 i 2.14959}$

\footnotetext{
${ }^{1}$ Doutoranda em Linguística pela Universidade Federal de Juiz de Fora.

${ }^{2}$ Professora associada da Universidade Federal de Juiz de Fora.
} 


\section{ESTUdOS LINGUÍSTICOS PARA O SÉCULO XXI}

"Querem convencer-nos de que existe uma forma correta de falar e escrever em espanhol, a forma de falar de determinados centros de dominação" ${ }^{3}$. Essa frase, proferida pelo escritor uruguaio Fábian Severo em entrevista ao Portal Galego da Língua em 2017, nos auxilia a compreender as nuances políticas e sociais que perpassam o uso do Portunhol na fronteira Brasil-Uruguai.

Conforme apontaremos posteriormente neste trabalho, desde meados dos anos 1970 época da ditadura militar no Uruguai — até o ano de 2003, a população que vive nas cidades que fazem fronteira com o Brasil foram impedidas de utilizar o Português em ambientes formais no Uruguai, entre eles, a escola. Desse modo, a língua materna desses sujeitos, o Portunhol, era considerada uma "deformação do idioma nacional" (BEHARES, 2007, p. 147 apud BORTOLINI; GARCEZ; SCHLATTER, 2013, p. 252) e deferia ser combatida.

A ideia de "uma nação-uma língua", cerne de uma ideologia linguística tradicional, denominada por Moita Lopes (2013) por linguística modernista, está relacionada à uma visão purista do que se convencionou chamar de língua, “com alarmantes implicações para ideologias de purificação das línguas e consequente inferiorização de classes sociais que não dominam a língua pura e legítima" (BAUMAN \& BRIGGS, 2003 apud MOITA LOPES, 2013). Ademais, as compreensões que envolvem essa concepção de língua não abrangem todas as transformações sociais, os contatos linguísticos fluídos e dinâmicos e os usos efetivos da linguagem que ocorrem no mundo globalizado atual (KUMARAVADIVELU, 2006). Para Moita Lopes (2013, p. 19),

essa perspectiva, adotada ainda por muitos estudiosos da linguagem, está relacionada epistemologicamente a teorizações típicas do século XX, que ignoram as avassaladoras teorizações sobre globalização, pós-modernidade, pós-estruturalismo, pós-colonialismo, feminismos, sexualidades, antirracismos etc., que estremeceram outros campos de investigação.

Isso vai ao encontro do que apontam Blommaert e Rampton (2011, p. 4), quando afirmam que

para compreendermos a intravisão sobre a transformação social que os fenômenos comunicativos podem nos oferecer, é essencial abordá-los com uma caixa adequada de ferramentas, reconhecendo que o vocabulário tradicional da análise linguística não é mais suficiente.

Assim, notamos a necessidade de teorizarmos enquanto linguistas atrelados à contemporaneidade, ao século XXI, a uma sociolinguística pós-moderna, baseada na etnografia e na

\footnotetext{
${ }^{3}$ Disponível em: http://pgl.gal/fabian-severo-querem-convencer-nos-existe-forma-correta-falar-escrever-espanholforma-falar-determinados-centros-dominacao/ Acesso em 13 jul. 2018.
} 
microanálise de práticas interacionais situadas, que valorizem os contextos onde os usos ocorrem (MOITA LOPES, 2013). Compreendendo, desse modo, que uma linguística que se pretende social, deve considerar os usos linguísticos efetivos do sujeito nos diversos contextos, ao invés de realizar análises com base em uma abstração de códigos marcados por territórios bem delimitados.

Neste contexto, o "uso" que se faz das línguas ${ }^{4}$ passa a ser compreendido dentro de construções linguísticas disponíveis em um vasto repertório relativo às vivências do sujeito e que se transformam continuamente. De acordo com Rymes (2014), o conceito de repertório linguístico relaciona-se a considerar a mobilidade da língua e de outros recursos semióticos no tempo e no espaço, compreendendo, assim, as línguas de forma integrada, enquanto "práticas translíngues" (CANAGARAJAH, 2013). Por meio desse enfoque, a pesquisa linguística passa a “enxergar” sujeitos que antes poderiam ser desconsiderados nos estudos justamente por não se encaixarem nas "caixas monolíngues", usualmente utilizadas por linguistas.

Portanto, é em meio a esse panorama que este trabalho pretende se inserir em uma linguística para o século XXI que, conforme nos aponta Moita Lopes (2013), está relacionada a uma abordagem que vai na direção de compreensões pós-estruturalistas, pós-modernistas e interpretativistas. As escolhas ideológicas que envolvem as reflexões qualitativas que serão realizadas nesta pesquisa estão ligadas às vivências das pesquisadoras e aos seus lugares de fala. Além disso, este estudo pretende ressoar de modo responsivo, como tentativa de combater desigualdades sociais por meio da linguagem, conforme nos sugere Norman Fairclough (1989[2001]), e como uma proposta de emancipação do sujeito por meio da valorização do seu repertório linguístico (RYMES, 2014).

Assim, através de uma proposta de compreensão sobre o poema "Trinticuatro", da obra "Noite nu Norte" (2011), de Fabián Severo, este estudo pretende refletir sobre os aspectos linguísticos e as questões de identidade presentes nessa literatura. $\mathrm{O}$ escritor uruguaio, nascido na cidade de Artigas - fronteira entre Brasil e Uruguai — defende que, "como em qualquer comunidade, é fundamental para as comunidades que falam Portunhol que exista literatura, música, educação em sua língua materna". ${ }^{5}$ Nesse sentido, esta pesquisa também objetiva ponderar sobre as relações entre arte e sociedade, especialmente sobre a relevância de se produzir uma literatura escrita em Portunhol, uma vez que, conforme afirma Antônio Cândido (1965[2014], p. 34), "percebe-se o movimento dialético que engloba a arte e a sociedade num vasto sistema solidário de influências recíprocas".

\footnotetext{
${ }^{4}$ A expressão "o uso que se faz das línguas" traz a reboque a noção de língua como "entidade" ou língua como ferramenta a ser usada. Não nos baseamos nessa noção. Entretanto, para fins de envolver nosso leitor em uma nova proposta de noção de língua precisamos recorrer à essa explicação neste trabalho.

5 Fonte: http://pgl.gal/fabian-severo-querem-convencer-nos-existe-forma-correta-falar-escrever-espanhol-forma-falardeterminados-centros-dominacao/ Acesso em 20 de julho de 2018.
} 
Embora as práticas linguísticas encontradas na fronteira sejam conhecidas popularmente como “dialecto, brasileiro, bayano o portuñol” (ELIZAINCÍN; BEHARES; BARRIOS, 1987 apud BORTOLINI; GARCEZ; SCHLATTER, 2013) e denominados tecnicamente como Dialectos Portugueses del Uruguay (ELIZAINCÍN; BEHARES, 1981 apud BORTOLINI; GARCEZ; SCHLATTER, 2013), neste trabalho serão denominados pelo termo "Portunhol”. Essa palavra será utilizada no âmbito desta pesquisa como uma proposta de desestigmatizar o termo, especialmente no âmbito acadêmico no qual é frequentemente associado a "falar mal". Nesse sentido, buscamos considerar a "natureza ideológica da construção do conhecimento" (MOITA LOPES, 2013, p. 22) ao realizar uma abordagem local entremeada pelo global. Desse modo, este trabalho objetiva contribuir para os estudos em sociolinguística e linguística aplicada, no entrelaçamento com os estudos literários.

Assim, este estudo será dividido da seguinte maneira: inicialmente faremos um breve histórico das políticas linguísticas educacionais no Uruguai; posteriormente questionaremos a perspectiva de "uma nação-uma-língua", ponderando sobre os enfoques dos repertórios linguísticos, das práticas translíngues no mundo atual globalizado e das identidades; então discutiremos a metodologia e, por fim, elencaremos caminhos de compreensão sobre o poema selecionado para reflexão.

\section{2. "Políticas Linguísticas eduCaCiOnais" No URUGUaI}

O breve histórico que será realizado nesta seção do trabalho debruçar-se-á, principalmente, no texto "Práticas linguísticas e identidades em trânsito: Espanhol e Português em um cotidiano comunitário escolar uruguaio na fronteira com o Brasil”, publicado por Letícia Bortolini, Pedro Garcez e Margarete Schlatter, em 2013.

O Portunhol, também conhecido popularmente pelos uruguaios como dialecto, brasilero o bayano (ELIZAINCÍN; BEHARES; BARRIOS, 1987 apud BORTOLINI; GARCEZ; SCHLATTER, 2013) é amplamente utilizado na fronteira Brasil-Portugal e tem passado por diversas transformações no modo como é nomeado e considerado em leis e pesquisas linguísticas desde meados dos anos 1970. Na época de sua ditadura militar (1973-1985), o Uruguai passou por forte repressão linguística, uma vez que, com a justificativa de defender uma identidade nacional, proibiu-se o uso do Português nas escolas e promoveu-se uma política linguística em prol do uso do Espanhol (BORTOLINI; GARCEZ; SCHLATTER, 2013).

Desse modo, a geração que frequentou a escola nesse período lidou com a proibição e o castigo pelo uso de sua língua materna na escola, em um incentivo ao combate às "deformações do 
idioma nacional". Contudo, nas cidades de fronteira entre Brasil e Uruguai os usos linguísticos não correspondem ao que se convencionou chamar de Espanhol e os cidadãos lidam com situações como essa, nas quais são impedidos de utilizarem sua língua materna, o Portunhol. Neste contexto, podemos ponderar sobre o modo como essa proibição afetou a formação escolar ${ }^{6}$, os usos linguísticos, os sentimentos sobre a língua e a identidade desses sujeitos. Refletiremos sobre esses temas na seção "Trinticuatro" deste trabalho.

Foi somente no ano de 2008 que mudanças foram realizadas nas políticas linguísticas educacionais e foi implementado o programa de ensino bilíngue (espanhol e português) em algumas escolas do norte do país. Segundo Bortolini, Garcez e Schlatter (2013, p. 252), "além do objetivo de formar alunos bilíngues, o Programa aponta para um objetivo social de valorização e respeito às variedades linguísticas trazidas à escola pela criança”. Contudo, conforme sabemos, é necessária uma mudança de comportamentos e atitudes sobre os repertórios linguísticos para desestigmatizá-los, uma vez que tal transformação não é realizada apenas pela implantação de políticas públicas (apesar de isso significar uma orientação para o sentido da mudança).

No que se relaciona à denominação dos usos linguísticos da fronteira, inicialmente Elizaíncin (1973 apud BORTOLINI; GARCEZ; SCHLATTER, 2013) descreveu a região como diglóssica, devido à coexistência de uma língua de menor prestígio e outra de maior prestígio. Já nos anos 1980, os estudos linguísticos sobre a região foram revisitados e sob o viés sociolinguístico variacionista passou-se a utilizar o termo Dialectos Portugueses del Uruguay (DPU), cunhado por Elizaincín e Behares (1981). “A abreviatura ficou consagrada, sendo amplamente utilizada tanto por linguistas quanto pelos próprios agentes educacionais ao se referirem às falas fronteiriças" (BORTOLINI; GARCEZ; SCHLATTER, 2013, p. 253). Entretanto, os DPU são muito estigmatizados socialmente apesar de serem, segundo Behares (2007, p. 126 apud BORTOLINI; GARCEZ; SCHLATTER, 2013, p. 254), "a língua materna de um conjunto muito amplo da população fronteiriça uruguaia, falas domésticas das famílias muitas vezes monolíngues".

Neste contexto, mudança muito significativa ocorreu em 12 de dezembro de 2008, quando foi implementada a Lei Geral de Educação no Uruguai, na qual aparece em seu texto a expressão “português do Uruguai”. Assim, notamos uma transformação no discurso da política linguística uruguaia no sentido de reconhecer a minoria linguística falante de português (BORTOLINI; GARCEZ; SCHLATTER, 2013). Contudo, as ideologias dos cidadãos uruguaios falantes de português sobre seus usos linguísticos seguem antigos padrões de estigmatização, demonstrando o

\footnotetext{
6 "Nos dados preliminares dos Censos 2011, os índices de analfabetismo nos departamentos do norte, mesmo em queda, seguem sendo os mais altos do Uruguai” (BORTOLINI; GARCEZ; SCHLATTER, 2013, p. 253).
} 
interesse desses sujeitos em falar "como falam os montevideanos" e, assim, terem seus repertórios linguísticos reconhecidos e valorizados ${ }^{7}$.

Na próxima seção, ponderaremos sobre a necessidade de teorizarmos linguisticamente de modo que abarquemos sujeitos que antes podem ter sido desconsiderados nos estudos linguísticos tradicionais devido à ideologia de "pureza das línguas" e às ideias atreladas à perspectiva de identidade nacional.

\section{Práticas translíngues, RePERTóRIOS LiNGUísticos E IDENTIDADE}

\section{Des}

Miña língua le saca la lengua al disionario baila un pagode ensima dus mapa i fas com a túnica i a moña uma cometa pra voar, livre i solta pelu seu.

Fabian Severo

A sociedade atual vem sendo caracterizada por vários estudiosos (KUMARAVADIVELU, 2006; BLOMMAERT, 2010; 2011, MOITA LOPES, 2013) como altamente dinâmica, fluida, cujos processos migratórios e os contatos linguísticos/sociais ocorrem intensamente. Além disso, é fato que a internet diminui as distâncias entre os sujeitos e possibilita acesso a uma quantidade enorme de informações e de entretenimento nos diversos idiomas (nos usos linguísticos que convencionalmente foram denominados como "línguas”). Conforme aponta Canagarajah (2013, p. 13, tradução nossa) as formas de globalização recente, por meio do

contato transnacional na diversidade cultural, na economia e nos domínios sociais têm ampliado a interação entre línguas e grupos linguísticos. A migração tem feito as pessoas levarem sua língua de herança para novos locais e, assim, há o desenvolvimento de repertórios que tradicionalmente não faziam parte de sua comunidade. Os desenvolvimentos tecnológicos facilitaram as interações entre grupos linguísticos e proporcionaram novos recursos para mesclar idiomas com outros sistemas simbólicos (ícones, emoticons, gráficos) e modalidades (imagens, vídeo, áudio) na mesma "página". Todos esses desenvolvimentos apresentam possibilidades interessantes e desafios para se comunicar através dos limites de idioma. Eles estão engendrando novos modos comunicativos à medida que as pessoas adotam estratégias criativas para envolverem-se umas com as outras e representarem suas vozes.

\footnotetext{
${ }^{7}$ Na pesquisa realizada entre 2007 e 2008 e publicada em 2013, Bortolini, Garcez \& Schlatter realizaram entrevistas com sujeitos que viviam na região fronteiriça e suas falas revelaram essas considerações.
} 
Nesse sentido, uma das consequências dessas características da contemporaneidade está relacionada aos efeitos linguísticos locais. Para Moita Lopes (2013, p.103), vivemos em um “mundo desterritorializado que faz surgir usos transdiomáticos do Português em meio a fronteiras físicas e cibernéticas, nas quais línguas, textos e pessoas estão em movimento. ”

Neste contexto, quando refletimos sobre os usos linguísticos realizados nas fronteiras, objeto de estudo deste trabalho, devemos considerar que, além dos cidadãos fronteiriços estarem em contato cotidiano com "duas línguas" e, portanto, sua língua materna ser composta por pedaços delas, potencialmente seu repertório linguístico (RYMES, 2014) é influenciado continuamente pela dinamicidade da tecnologia nos dias de hoje e pela globalização atual (KUMARAVADIVELU, 2006). Assim, conforme nos orienta Rymes (2014, p. 3),

múltiplas línguas, múltiplas maneiras de falar a "mesma" língua e muitos outros elementos além da língua podem servir como parte de um repertório comunicativo individual que possui o potencial de criar alinhamentos comunicativos ou crosstalk em qualquer interação. Enquanto Gumperz usava o termo repertório linguístico para descrever a circulação de línguas em uma comunidade, atualmente, o uso do termo "repertório" tem se tornado um modo comum de descrever como os indivíduos empregam outros modos de comunicação em adição as suas múltiplas línguas.

Assim, mediante ao cenário linguístico em que vivemos na globalização atual (KUMARAVADIVELU, 2006), é necessário pensarmos os repertórios dentro de uma perspectiva sociolinguística que considere os trânsitos e fluxos de textos e de pessoas. Precisamos adotar uma visão de linguagem que a considere como prática local, um produto de atividades profundamente sociais e culturais nas quais as pessoas se engajam (PENNYCOOK, 2010). Nesse sentido, é a prática que faz a língua existir assim como o falante e o escritor, já que a linguagem não preexiste ao uso e ao sujeito, contrariamente ao que normalmente é assumido pelos estudos linguísticos (MOITA LOPES, 2013).

É nesse sentido que este estudo considera que os sujeitos agem por meio dos seus repertórios em sociedade, e performam suas identidades por meio do discurso, através de práticas translíngues. Canagarajah (2013) adota o termo translanguaging ${ }^{8}$ para denominar os usos linguísticos dos falantes que revelam relações entre — o que se convencionou denominar — idiomas/línguas. Contudo, para o autor, "a comunicação transcende as línguas individuais, transcende as palavras e envolve diversos recursos semióticos e possibilidades ecológicas"9. (CANAGARAJAH, 2013, p.18, tradução nossa). $\mathrm{O}$ autor aponta ainda que todos nós somos translíngues em diferentes níveis, pois todas as

\footnotetext{
${ }^{8}$ Neste trabalho, optamos por traduzir o termo translanguaging por "prática translingue"

9 "Firstly, communication transcends individual languages. Secondly, communication transcends words and involves diverse semiotic resources and ecological affordances" (CANAGARAJAH, 2013, p. 18, como no original).
} 
comunidades e comunicações são heterogêneas e, assim, se influenciam mutuamente, e consequentemente todas as línguas estão em constante processo de mudança e hibridização, principalmente no complexo mundo atual (CANAGARAJAH, 2013).

Segundo Santos (2017, p. 529), as práticas translíngues "atravessam fronteiras linguísticas, políticas e simbólicas para os falantes construírem o sentido dos seus mundos”. Desse modo, somos seres que se constroem no discurso e que performam identidades construídas aqui e agora (MOITA LOPES, 2006, 2013). Nesse sentido, não podemos refletir sobre as identidades associando-as às fronteiras políticas nacionais e às concepções monolíngues de línguas, uma vez que a demarcação de fronteiras e a divisão geopolítica do mundo não corresponde às realidades locais, às práticas situadas.

A identidade (SILVA, 2011) é, portanto, relação social, resultado de produção simbólica e discursiva, sujeita a vetores de força, a relações de poder. A diferença pode ser construída negativamente - por meio da exclusão ou da marginalização dos sujeitos que são construídos como "outros". "Questionar a identidade e a diferença como relações de poder significa problematizar os binarismos em torno dos quais elas se organizam (SILVA, 2011, p. 83). ”

Assim, é envolvida neste quadro teórico que esta pesquisa busca propor caminhos de compreensão para os usos linguísticos, as performances identitárias e os sentidos sociais e simbólicos locais existentes no poema "Trinticuatro" do poeta Fabián Severo. Na próxima seção, apresentaremos a metodologia selecionada para as reflexões deste estudo.

\section{Perspectiva Qualitativa de Pesquisa}

O viés qualitativo de pesquisa, adotado neste estudo, considera que a busca pela neutralidade ao discutir sobre os dados é talvez inalcançável, e isso se acentua se o objeto em reflexão se trata da linguagem que, conforme sabemos, está intrinsicamente associada ao meio social ao qual o sujeito está inserido. Nesse sentido, a pesquisa qualitativa procura refletir sobre o objeto de análise de modo a considerar o olhar do pesquisador sobre os dados (DENZIN; LINCOLN, 1994), de modo que a subjetividade de quem analisa o corpus é parte da pesquisa e não pode ser eliminada.

O olhar qualitativo para fenômenos do mundo considera, portanto, que apenas parte da realidade pode ser apreendida e isso acontecerá de maneira parcial e influenciada pelo lugar do sujeito na historicidade. Sendo assim, considerando os vários fatores que influenciam na sua realização, a pesquisa qualitativa não objetiva ser um estudo de caráter universal, nem mesmo busca encontrar respostas gerais para hipóteses pré-estabelecidas. Mas, procura usar métodos que busquem interpretar os acontecimentos, uma vez que "tudo que se pode saber do mundo, mesmo que se saiba pela ciência 
é sabido a partir de uma visão própria ou de uma experiência do mundo" (MERLEAU-PONTY, 1999, p. 3).

Assim, este estudo pretende lançar um olhar demorado sobre o poema "Trinticuatro", do livro "Noite nu Norte" do escritor uruguaio Fabián Severo, refletindo sobre o os usos linguísticos presentes no texto, e discutir sobre as performances identitárias locais construídas a partir dos sentidos do poema. A seleção desse poema foi motivada pela relação afetiva entre língua e memória que o eu do poema parece construir ao longo das estrofes. Na próxima seção, discorreremos sobre o poeta Fabián Severo.

\section{O POETA E A FRONTEIRA}

Fabian Severo nasceu na cidade de Artigas, fronteira do Brasil com o Uruguai, em 1981. É autor dos livros Noite nu Norte. Poemas en Portuñol (Rincón, 2011), Viento de Nadie (Rumbo Editorial, 2013), NósOtros (Rumbo Editorial, 2014) e Viralata (2015). Parte de sua obra tem sido publicada no Brasil, em Cuba, Argentina e Estados Unidos. Ademais, recebeu o prêmio Morosoli de Bronce, na categoria poesia em 2010 e foi um dos ganhadores do Fondo de Estímulo a la Creación Artística em 2012. Atualmente é docente de literatura em Montevideo e coordenador de oficinas de escrita. ${ }^{10}$

A vivência na fronteira até a idade adulta parece ter influenciado significativamente a relação do poeta com a sua língua e a sua identidade. Enquanto fronteiriço, o autor não é falante do que se convencionou denominar português, nem do espanhol, apesar de carregar em sua nacionalidade o registro de uruguaio. Na prática, Fabián não é “nem de lá nem de cá”, mas uma mistura dos dois que politicamente e socialmente vem sendo estigmatizada desde a criação dos estados nacionais. Conforme aponta Souza \& Carvalho (2010, p. 114),

o imponderável da fronteira encontra-se nos acontecimentos possíveis de sua transigência que, no lugar de delimitar um território qualquer, estende a sua cartografia por passagens que, em um dado momento, mesclam e combinam com (posições) de espaço e de tempo. A fronteira é uma ficção, portanto. É um nome dado a linhas abstratas que, na realidade, não existem como são; turvamento contínuo do que lhe escapa incessantemente: microfísica de mobilidades contínuas.

Sobre a fronteira, Severo $(2017)^{11}$ afirma:

\footnotetext{
${ }^{10}$ Fontes: https://www.escaramuza.com.uy/poesia/item/tres-poemas-de-fabian-severo.html https://fabiansevero.webnode.com.uy/biografia/ Acesso em 21 de julho de 2018.

${ }^{11}$ Fonte: CRINÒ, Cristiana. O Portunhol/Portuñol na poesia de Fabián Severo. Atas do V Simelp - Simpósio Mundial de Estudos de Língua Portuguesa. 2017, p.2141-2157.
} 
Yo no sé qué es la frontera. Tal vez, la frontera sea varios lugares; una forma de mirar; un lugar donde los mapas se pegan o se despegan; un estuario, donde el agua dulce del río se mezcla con el agua salada del mar, allí crecen especies que no crecen en otros lugares, los fronterizos somos esas especies. Tal vez la frontera no sea. Nosotros, los "frontera", vemos que los conceptos se desarman, que lo que algunos llaman "patria", "país", "nación", "idioma", no significa lo mismo para nosotros. Como dice el poeta "si me preguntan ¿qué es mi patria ¿, diré no sé."

A literatura produzida na "fronteira" carrega uma mistura de temas e sentimentos, pedaços de "línguas" que se transformam em um emaranhado de sentidos que expressam um fazer poético. Assim, a fronteira cria uma nova identidade. Fabián Severo, quando questionado sobre a escrita em Portunhol ${ }^{12}$, afirma:

o portunhol é a minha verdadeira língua materna. É aquela que eu escutava quando estava no ventre da minha mãe e aquela que aprendi a falar nos primeiros anos de vida, antes da alfabetização formal. Quando estou sentimental, uso o portunhol. É o idioma mais urgente, o dos meus afetos.

Nesse trecho, o poeta explica a importância do uso do Portunhol em sua poesia, apontando a relação afetiva que estabelece com a língua e demonstrando como suas memórias estão diretamente relacionadas ao contexto de uso desse repertório linguístico. Contudo, ao utilizar o Portunhol em seus escritos, o poeta vai de encontro às perspectivas monolíngues de língua e de nação, e perturba modelos tradicionalmente construídos e que convencionalmente caracterizam "a cultura do Uruguai". Desse modo, o que devemos questionar enquanto linguistas é: o que se consagrou como "língua/cultura" de um país corresponde à realidade, às práticas cotidianas locais ou apenas a uma comunidade que foi imaginada?

Na próxima seção, refletiremos sobre o poema "Trinticuatro" e buscaremos, a partir de um estudo local, encontrar caminhos de compreensão para a literatura em portunhol.

\subsection{Trinticuatro}

Mi madre falava mui bien, yo intendía.

Fabi andá faser los deber, yo fasía.

Fabi traseme meio litro de leite, yo trasía.

Desí para dona Cora que amañá le pago, yo disía.

Deya iso gurí i yo deiyava.

\section{Mas mi maestra no intendía.}

12 Fonte: https://gauchazh.clicrbs.com.br/cultura-e-lazer/noticia/2014/09/Artistas-usam-portunhol-da-fronteira-BrasilUruguai-para-criar-obras-liricas-e-singulares-4591649.html Acesso em 21 de julho de 2018. 
Mandava cartas en mi cuaderno todo con rojo (igualsito su cara) i asinava imbaiyo.

Mas mi madre no intendía.

Le iso para mi mijo y yo leía.

Mas mi madre no intendía.

Que fiseste meu fio, te dice que te portaras bien

i yo me portava.

A historia se repitió por muintos mes.

Mi maestra iscrevía mas mi madre no intendía.

Mi maestra iscrevía mas mi madre no intendía.

Intonse serto día mi madre intendió i dice:

Meu fío, tu terás que deiyá la escuela

i yo deiyé

Ao refletirmos sobre o poema "Trinticuatro", algumas considerações nos parecem relevantes: os sentidos de memória e afeto presentes na escrita; a valorização do Portunhol como língua materna e seu uso linguístico legítimo; a crítica à escola enquanto instituição linguisticamente repressora; os usos linguísticos presentes no poema, marcados pela prática translingue.

Nesse sentido, a primeira estrofe do poema afirma que a mãe falava bem, era compreendida, e seus usos linguísticos eram suficientes para agir em sociedade: Mi madre falava mui bien, yo intendía /Fabi andá faser los deber, yo fasía /Fabi traseme meio litro de leite, yo trasía /Desí para dona Cora que amañá le pago, yo disía /Deya iso gurí i yo deiyava. Os versos revelam a nostalgia de um cotidiano tranquilo na relação afetiva com sua mãe, por meio de imagens do passado.

Já na segunda estrofe, há a inserção da professora de Fabián na narrativa, e nas estrofes seguintes (terceira e quarta) o eu do poema demonstra que entre sua mãe e a professora havia dificuldades de entendimento: Mas mi maestra no intendía/ Mandava cartas en mi caderno/ todo con rojo (igualsito su cara) i asinava imbaiyo /Mas mi madre no intendía/ Le iso para mi mijo y yo leia/Mas mi madre no intendía/Que fiseste meu fío, te dice que te portaras bien/ $i$ yo me portava. Nesse trecho do poema, notamos a instituição escola colocando-se como detentora do "falar correto" e a mãe posicionandose como representante de um uso linguístico "inadequado". Isso demonstra uma das consequências de se caracterizar o Uruguai como um território unificado e monolíngue, 
já que são vários os repertórios linguísticos particulares presentes nos usos reais dos sujeitos. Por meio dessa caracterização, os indivíduos que não fazem parte da norma linguística institucionalizada são apagados e suas identidades desconsideradas.

A terceira estrofe, por sua vez, parece demonstrar o modo como esse “desentendimento" linguístico perdurava na época escolar, de modo que a repetição do verso implica em repetição do acontecimento: A historia se repitió por muintos mês /Mi maestra iscrevía mas mi madre no intendía /Mi maestra iscrevía mas mi madre no intendía. Desse modo, esse trecho implica que a escola não se preocupava em buscar outros meios de compreensão entre os usos linguísticos fronteiriços (usos reais) e os usos considerados legítimos, ocupando um lugar de "autoridade linguística" na vida da família e desconsiderando a língua materna local.

Por fim, a última estrofe do poema performa uma mudança inesperada: Intonse serto día mi madre intendió i dice: Meu fío, tu terás que deiyá la escuela / i yo deiyé. $\mathrm{E}$ demonstra a percepção da mãe de que não haveria um caminho de compreensão com a instituição escolar e que deixá-la seria a melhor alternativa. Para Crinò (2017, p. 2152), os últimos três versos do poema são "uma metáfora perfeita da lealdade que o poeta quer manter pela sua língua de origem”. Além disso, conforme comentado neste trabalho anteriormente, de meados dos anos 1970 à meados dos anos 2000 houve a proibição do uso do Português e do Portunhol nas escolas uruguaias e o período escolar do poeta está inserido nesse recorte temporal. Assim, podemos perceber os reflexos do impedimento do uso de sua língua materna na vida do autor, na melancolia do poema, na nostalgia e na desvalorização do seu falar social. Para Antônio Candido (1965[2014]),

a arte é social em dois sentidos: depende da ação de fatores do meio, que se exprimem na obra em graus diversos de sublimação; e produz sobre os indivíduos um efeito prático, modificando a sua conduta e concepção do mundo, ou reforçando neles o sentimento dos valores sociais.

No que tange aos usos linguísticos presentes no poema, o repertório linguístico é marcado por práticas translíngues que, conforme aponta Canagarajah (2013), transcendem as línguas individuais e envolve diversos recursos semióticos. $\mathrm{O}$ autor afirma ainda que as línguas em contato se influenciam mutuamente, e rotulá-las como entidades separadas é um ato ideológico. Consideramos, então, que os usos linguísticos presentes em "Trinticuatro" não se referem ao sistema de duas línguas separadas, mas 
sim a recursos semióticos misturados e que, juntos, performam sentidos e constroem identidades.

Dessa forma, performances identitárias estão sendo localmente construídas nas práticas situadas, por meio de indexicalizações (por meio de escolhas lexicais, gramaticais, fonológicas, entonacionais, etc.), que estilizam o significado no mundo social (MOITA LOPES, 2013). O poema de Fabián Severo clama por legitimação de sua "língua materna", a "língua" do seu povo, na qual construiu seu conhecimento sobre o mundo. Ademais, as escolhas linguísticas presentes no poema revelam uma reflexividade metapragmática por parte do autor que transparece suas compreensões sobre língua. Compreensões essas que se demonstram distantes do mito de "uma-nação-uma-língua".

É nesse sentido que as reflexões realizadas no âmbito deste trabalho estão localizadas dentro do que denominamos uma linguística para o século XXI (inspirados em MOITA LOPES, 2013). Desse modo,

ao desafiar o ideal de uma língua pura, focalizando o linguajar, essa posição teórica colabora para abrir espaço para problematizar "as vozes dos debaixo", que tradicionalmente foram e são mantidas de forma cristalizada, por tal ideal. [...]. Tal problematização é possível ao teorizar escritores, falantes, etc. em seus atravessamentos identitários performativos de classe social, de gênero, raça, sexualidade, nacionalidade etc., os quais por sua natureza performativa não preexistem às práticas discursivas situadas e, como tais, não podem ser compreendidos como sedimentos (MOITA LOPES, 2013, p. 119).

Essa perspectiva epistêmica relaciona-se a pensar uma linguística em prol dos direitos humanos, em uma tentativa de minimizar desigualdades sociais, emancipar e dar voz aos sujeitos. Atrelada a isso, está a valorização da produção literária escrita em Portunhol, que se situa de modo relevante dentro da realidade sociolinguística fronteiriça, apresentando temas, personagens e cenários que só adquirem sentido se escritos de tal modo. Antonio Candido, em seu texto "direito à literatura" (2000, p. 175) comenta sobre a importância da literatura para as sociedades e afirma que

assim como não é possível haver equilíbrio psíquico sem o sonho durante o sono, talvez não haja equilíbrio social sem a literatura. Deste modo, ela é fator indispensável de humanização e, sendo assim, confirma o homem na sua humanidade [...]. Neste sentido, ela pode ter importância equivalente à das formas conscientes de inculcamento intencional, como a educação familiar, grupal ou escolar. Cada sociedade cria as suas manifestações ficcionais, poéticas e dramáticas de acordo com seus impulsos, suas crenças, os seus sentimentos, as suas normas, a fim de fortalecer em cada um a presença e atuação deles. 
Notamos assim a relevância da literatura escrita em Portunhol. Uma literatura que possibilita que a população fronteiriça se sinta representada, que veja seu cotidiano transformado em arte. E na qual leitores diversos podem descobrir novos mundos possíveis de experiências estéticas e de sentido.

\section{Algumas CONSIDERAÇões ATÉ AQUI}

Este trabalho procurou realizar uma abordagem local entremeada pelo global e, desse modo, propor caminhos de compreensão sobre o repertório linguístico presente na literatura escrita em Portunhol, considerando a prática translingue que a envolve. Assim, demonstramos por meio das reflexões sobre o poema "Trinticuatro" do autor Fabián Severo, que os estudos linguísticos tradicionais, fincados no conceito de língua enquanto categoria abstrata, não dão conta de ponderar sobre as práticas locais e as performances identitárias que ocorrem localmente em sociedade.

Ademais, ponderamos sobre a relevância da produção literária em Portunhol, apontando a literatura como um direito dos indivíduos, além de expressão de realidades profundas presentes na subjetividade do autor. Afirmamos, nesse sentido, que valorizar os usos linguísticos locais pode contribuir para minimizar as desigualdades sociais e emancipar os sujeitos.

\section{REFERÊNCIAS}

BLOMMAERT, J. 2010. The Sociolinguistics of Globalization. New York, Cambridge University Press, 229 p. DOI http://dx.doi.org/10.1017/CBO9780511845307 BLOMMAERT, J.; RAMPTON, B. Language and Superdiversity. Diversities, v. 13, n. 2, p. 1-21, 2011.

CANAGARAJAH, S. Translingual practice: global englishes and cosmopolitan relations. London/New York: Routledge, 2013.

CANDIDO, Antonio. Direito à literatura. In: CANDIDO, Antonio. Vários escritos. São Paulo: Duas Cidades, 2000

CANDIDO, Antonio. Literatura e Sociedade: Estudos de Teoria e História

Literária. Rio de Janeiro: Ouro sobre Azul. 1965[2014].

CRINÒ, Cristiana. O Portunhol/Portuñol na poesia de Fabián Severo. Atas do V Simelp - Simpósio Mundial de Estudos de Língua Portuguesa. 2017, p. 2141-2157.

DENZIN; Y. S.; LINCOLN (org.). Handbook of Qualitative Research. California, SAGE Publications, 1994. 
FAIRCLOUGH, N. Language and power. London: Longman, 1989. Pearson Education, 2001.

KUMARAVADIVELU, B. A linguística aplicada na era da globalização. In: MOITA LOPES, L. P. (org). Por uma Linguística Aplicada Indisciplinar. São Paulo: Parábola, 2006.

MERLEAU-PONTY, M. Fenomenologia da percepção. São Paulo: WSF Martins Fontes, 1999.

MOITA LOPES, Luiz Paulo da. (Org). Por uma linguística aplicada indisciplinar. São Paulo: Parábola editorial, 2006.

MOITA LOPES, Luiz Paulo da. Como e por que teorizar o português: recurso comunicativo em sociedades porosas e em tempos híbridos de globalização cultural. In: MOITA LOPES, L.P. O português no século XXI: cenário geopolítico e linguístico. São Paulo: Parábola editorial, 2013. p. 101-119.

MOITA LOPES, Luiz Paulo da; BORTOLINI, Letícia Soares; GARCEZ, Pedro M.; SCHLATTER, Margarete. Práticas linguísticas e identidades em trânsito: Espanhol e Português em um cotidiano comunitário escolar uruguaio na fronteira com o Brasil. In: MOITA LOPES, L.P. O português no século XXI: cenário geopolítico e linguístico. São Paulo: Parábola editorial, 2013. p. 249- 273.

RYMES, B. Communicative repertoire. In: C. LEUNG; B.V. STREET (ed.). The Routledge Companion to English Studies. London: Routledge, 2014. Disponível em: https://upenn.academia.edu/BRymes. Acesso em: 01 set. 2014.

SANTOS, Maria Elena Pires. Portunhol Selvagem: translinguagens em cenário translíngue/transcultural de fronteira. Gragoatá, Niterói, v. 22, n. 42, p. 423-539, jan./abr. 2017

SILVA, Tomaz Tadeu da. Identidade e Diferença: A Perspectiva dos estudos culturais. 15. ed. Petrópolis, RJ: Vozes, 2011. 